\title{
A community based pilot study on prevalence of hemoglobinopathies among the antenatal women in a rural area of Darjeeling district, West Bengal
}

\section{Nilanjana Ghosh, Indranil Chakrabarti ${ }^{1}$, Manasi Chakraborty, Bidyut K. Goswami²}

Departments of Community Medicine, ${ }^{1}$ Pathology, North Bengal Medical College,

Sushrutanagar, Darjeeling, ${ }^{2}$ Department of Pathology, Nilratan Sircar Medical College, Kolkata, West Bengal, India

Address for the Correspondence:

Dr. Indranil Chakrabarti, Department of Pathology, North Bengal Medical College,

Sushrutanagar, Darjeeling, West Bengal, India. E-mail: drinch@rediffmail.com

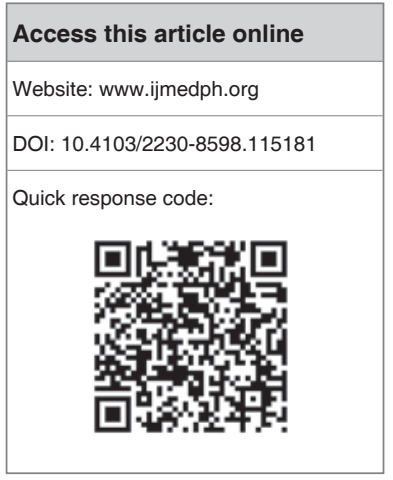

\begin{abstract}
Background: Hemoglobinopathies comprising of thalassemias and various hemoglobin $(\mathrm{Hb})$ variants continue to plague the health system of India. Aims: To find out the prevalence of various hemoglobinopathies in the study population and to identify any association with the various ethnic groups residing in rural community of Darjeeling district, West Bengal. Materials and Methods: A community-based cross-sectional study was conducted in Naxalbari block of Darjeeling district, West Bengal from June 2011 to August 2011, involving hemoglobin variant screening by high-performance liquid chromatography (HPLC) method of 188 antenatal women, selected through multistage random sampling technique. Results: $26.6 \%$ of mothers had abnormal hemoglobin, the commonest being the Hemoglobin $E(H b E)$ trait $(15.42 \%)$. The prevalence of homozygous $\mathrm{HbE}, \mathrm{HbE} \beta$ thalassemia, $\beta$-thalassemia trait and hemoglobin S-trait in the studied population was $6.91 \%, 0.53 \%, 2.12 \%$ and $1.06 \%$ respectively. There was a single case of the rare hemoglobin J Meerut. Among those having abnormal hemoglobin, $66 \%$ belonged to one ethnic group, Rajbanshis. A statistically significant association was noted between $\mathrm{Hb}$ E syndrome (comprising of $\mathrm{HbE}$ trait, homozygous $\mathrm{HbE}, \mathrm{HbE}$-betathalassemia) and Rajbanshis $(P<0.05)$. Conclusion: Findings suggest a high prevalence of hemoglobinopathies particularly $\mathrm{Hb} \mathrm{E}$ in the studied population, especially Rajbanshis and warrant the need of wider community-based initiative for carrier detection and awareness generation.
\end{abstract}

Key words: Antenatal women, hemoglobinopathies, high-performance liquid chromatography, screening

\section{INTRODUCTION}

India is a vast country with considerable regional and ethnic diversity catering approximately a population of 1.2 billion. The inherited hemoglobinopathies, namely hemoglobin (Hb) variants, thalassemia syndromes, hereditary persistence of fetal hemoglobin (HPHF) and their combinations show a wide variation of prevalence in the different regions and different populations. Around $1.5 \%$ of the world's population carries the beta thalassemia gene. In India, nearly 30 million people are carriers of beta thalassemia and 7,000 babies with beta-thalassemia major are born every year. ${ }^{[1,2]}$ The South-East Asia region (including India, Thailand, Indonesia) accounts for 50\% of world's thalassemia carriers ${ }^{[3]}$ and for maximum of hemoglobin $\mathrm{E}(\mathrm{HbE})$ cases. $\mathrm{Hb} \mathrm{E}(\boldsymbol{\beta}-26$ glutamine $\rightarrow$ lysine) is a structural variant of hemoglobin which in combination with thalassemia trait can manifest clinically as thalassemia minor, intermedia or major. The thalassemia major and few cases of thalassemia intermedia require repeated blood transfusions and are a major cause morbidity and mortality. In absence of a complete cure, carrier detection and hence prevention remains the mainstay. The carrier rate of beta-thalassemia varies between 0 to $17 \%$ in different ethnic groups. ${ }^{[4]}$ Among antenatal women, prevalence of beta thalassemia carrier rate was found to be $8.45 \%$ by Desai et al. ${ }^{[5]}$ and $5.8 \%$ by Sinha, et al. ${ }^{[6]}$ In a community based study in West Bengal in 2006, Sur et al. found the prevalence of carrier state to be 5.95\% among antenatal women. ${ }^{[7]}$ Among Hbvariants, $\mathrm{Hb} \mathrm{D}$ is more common in northern part of India (particularly Punjab) and $\mathrm{Hb} \mathrm{S}$ in tribal areas. $\mathrm{Hb} \mathrm{E}$ (comprising of HbEhomozygous state, HbE heterozygous state or $\mathrm{Hb}$ 
E trait and other double heterozygous states with $\mathrm{Hb} \mathrm{E}$ ) is the commonest hemoglobin variant in the northeastern region of India with a prevalence of $7-50 \% \cdot{ }^{[8]}$ Hemoglobin $\mathrm{E}$ has a prevalence of $3-10 \%$ in West Bengal ${ }^{[0]}$ and is believed to be harbored mostly by Rajbanshis, who form the majority of the local population living in the northern part of the state. Beta thalassemia screening program with help of high pressure liquid chromatography technique (HPLC) help in awareness generation, carrier detection and genetic counseling and can create an effective database for the region. However, there being dearth of any published literature on this grave issue in this rural community of Darjeeling district, this study was envisaged. Objectives of the study were to determine the prevalence of various hemoglobinopathies among antenatal women residing in the study area and find out if any significant association exists between them and various ethnicities residing in the area along with awareness generation in the community.

\section{MATERIALS AND METHODS}

A cross-sectional community based study was undertaken in the Naxalbari block of Siliguri subdivision, Darjeeling district, West Bengal for three months (June to August 2011). Serving a population of approximately 120,000 , it is divided into six GPs (Gram Panchayats) which is further subdivided into 15 sub-centers. Using multistage random sampling technique, one-third GPs, i.e., two GPs serving six sub-centers were selected. Subsequently one-third of the sub-centers, i.e., two sub-centers from the selected GPs were further selected, catering approximately 4,500 and 5,200 population. All the villages of these sub-centers were included. Requisite permission was obtained from ethical committee, Department of Community Medicine and concerned block medical officer of health $(\mathrm{BMOH})$. With the help of the frontline workers a village-wise list of all antenatal mothers was prepared. Birth rate of the block was 18 at the time of study. Applying a design effect of 2 and taking a non response rate of $10 \%$ the final sample size was calculated to be 188. Thus, 188 antenatal women attending the screening camp were the study subjects. Sensitization campaigns were held prior to organizing the screening camps. The women and their families were explained and counseled to attend the beta-thalassemia screening program (held with aid of Thalassemia Control Unit) on stipulated dates. Apart from screening, awareness generation and counseling with help of counselors appointed under the Thalassemia Control Unit was also conducted simultaneously. Those mothers who were not permanent residents of the area, unwilling to give consent for participation the study, outside $20^{\text {th }}$ week of gestation, seriously ill or had received blood transfusion within six weeks were excluded from the study. A written informed consent was taken from the willing participants. Using a pretested, semi-structured interview schedule, a detailed history was obtained from the mothers with special reference to caste and ethnicity. The blood samples were collected, transported and run in the automated cell counter (Sysmex KX 21) as well as HPLC machine (Variant, Bio-Rad, USA using the beta thalassemia short program) as per standard operating procedure. A value of $3.5 \%$ of $\mathrm{A}_{2} / \mathrm{E}$ fraction of hemoglobin was taken as cut off point for determining the beta thalassemia trait. ${ }^{[10]}$ The results were recorded. The reports of the blood tests were handed to antenatal women at their home by help of their respective health field functionaries like Accredited Social Health Activist (ASHA), Anganwadi workers (AWW), Auxiliary Nurse Midwives (ANM) within 15 days. Parental study, DNA study, spousal testing was recommended as and when required. Posters, pamphlets and informative materials in local languages regarding benefits of free of cost premarital screening, prenatal screening and importance of carrier detection was given in the community for widespread awareness generation.

\section{RESULTS AND ANALYSIS}

A total of 188 antenatal women, pertaining to study criteria, were screened over three months. The mean age distribution was $22.98 \pm 4.5$ years with a range of $17-44$ years. A total of 105 women were in their first trimester and 83 were in second trimester. While the majority of the studied populations were Rajbanshis (41.48\%), $20.74 \%$ belonged to other hill tribes including Adivasis. Among total 188 women, 50 women $(26.6 \%)$ had abnormal reports [Table 1]. $15.95 \%$ of women in first trimester and $10.63 \%$ of those in second trimester had hemoglobinopathies. The overall prevalence of $\mathrm{Hb}$ E-trait, Hb E-homozygous, Hb E-beta thalassemia, beta thalassemia trait and $\mathrm{Hb}$ S-trait was 15.42\%, 6.91\%, 0.53\%, 2.12\% and 1.06\% respectively. One rare case of $\mathrm{HbJ}$ Meerut was detected. Her parental study was done and her mother was also found to have $\mathrm{HbJ}$ Meerut. Her DNA study was advised as it was not done in North Bengal Medical College and Hospital. Among total 41.48\% of population being represented by Rajbanshis, prevalence of $\mathrm{Hb}$ E-trait was $23.07 \%$, Hb E-homozygous was 12.82\%, HbE-beta thalassemia was $1.28 \%$ and beta thalassemia trait was $2.56 \%$. The

\begin{tabular}{|c|c|c|c|c|}
\hline Abnormal Hb. variants & Rajbanshis (\%) & Hilltribes and adivasis (\%) & General-caste (\%) & Total \\
\hline E trait & $18(23.37)$ & $07(17.94)$ & $04(05.63)$ & 29 \\
\hline EE disease & $10(12.98)$ & $02(05.12)$ & $01(01.40)$ & 13 \\
\hline Beta thalassemia trait & $02(02.59)$ & 00 & $02(02.80)$ & 04 \\
\hline E beta thalassemia & $01(01.29)$ & 00 & 00 & 01 \\
\hline $\mathrm{Hb} \mathrm{J}$ Meerut & $01(01.29)$ & 00 & 00 & 01 \\
\hline $\mathrm{Hb} \mathrm{S}$ & $01(01.29)$ & 00 & $01(01.40)$ & 02 \\
\hline TOTAL & $33(42.85)$ & 09 (23.07) & $08(11.26)$ & 50 \\
\hline
\end{tabular}

$\mathrm{Hb}=$ Hemoglobin 


\begin{tabular}{|c|c|c|c|c|}
\hline $\begin{array}{l}\text { Population } \\
\text { pattern }\end{array}$ & $\begin{array}{l}\mathrm{HbE} \text { and its } \\
\text { derivatives }\end{array}$ & $\begin{array}{l}\text { Others (normal and } \\
\text { non-HbE variants) }\end{array}$ & Total & $\begin{array}{l}\text { Significant statistical } \\
\text { association noted }\end{array}$ \\
\hline Rajbanshis & 29 & 49 & 78 & \multirow{3}{*}{$\begin{array}{l}\text { Chi-square test=15.47, } \\
\mathrm{df}=1, P<0.05(0.00) \text { ODDS } \\
\text { RATIO }=4.06,95 \% \mathrm{Cl}(1.86-8.95)\end{array}$} \\
\hline Non-rajbanshis & 14 & 96 & 110 & \\
\hline Total & 43 & 145 & 188 & \\
\hline
\end{tabular}

$\mathrm{HbE}=$ Hemoglobin $\mathrm{E}$

prevalence of $\mathrm{HbJ}$ and $\mathrm{HbS}$ was $1.28 \%$ each. Thus, the overall prevalence of HbEhemoglobinopathies among Rajbanshis was $37.17 \%$ (Hb E trait, Hb E homozygous and $\mathrm{Hb}$ E-beta thalassemia). Bivariate analysis applying Chi-square test revealed that a statistically significant $(P<0.05)$ association was found between the Rajbanshi population and prevalence of HbEhemoglobinopathies. $(P=0.00$, $\mathrm{df}=1$, Pearson's Chi-square coefficient $=15.47$, Odds Ratio $=4.06$, C.I $=1.86-8.95)$ [Table 2]. No statistically significant association was found between hemoglobinopathies and the other ethnic groups $(P>0.05)$.

\section{DISCUSSION}

Community based studies are representative of the actual situation prevailing in the area, as the tests and interviews are carried out in their natural settings. In this study, it was observed that reporting of spouses and parents whenever required was more if the camps were held near to their residence. Rajbanshis emerged as of the most predominant ethnic group in this area. They are survivors of an aboriginal race. ${ }^{[11]}$ In this study, a significant association between Rajbanshis and HbEhemoglobinopathies was found $(P<0.05)$. Prevalence of $\mathrm{HbE}$ trait was found to be highest amongst all the hemoglobinopathies. Increased occurrence of $\mathrm{HbE}$ in this area is similar to found in Assam and Tripura ${ }^{[8,12]}$ hinting at lineage simulation between the Rajbanshis and these states. Hill tribes, mainly Adivasis, also showed a high HbE occurrence, thus indicating intra racial marriages with Rajbanshis and acculturation. Adivasis, who immigrated into Northern part of West Bengal for tea cultivation from Chotanagpur plateau, their results also match with the residents of central east coast of India. ${ }^{[11,13]}$ The overall prevalence of HbEbeta thalassemia and HbEhomozygous state are found to be of lesser magnitude but need special emphasis to avoid their contribution to fatal disease. The clustering of hemoglobinopathies may be due to small population size, caste endogamy, consanguinity, virtual lack of medical facilities and natural barriers like rivers, forests. One surprising and incidental finding was that of $\mathrm{Hb} \mathrm{J}$-Meerut which is a rare fast moving variant of $\alpha$ chain of hemoglobin which results from a C ->A mutation (GCG->GAG) at codon 120 of the $\alpha 1$ or $\alpha 2$ globin gene, changing the alanine to glutamic acid at residue 120 of the $\alpha$ chain. The subject had an elevated P3 window with an abnormal hemoglobin peak of $38.8 \%$ with a retention time of $1.84 \mathrm{~min}$. A possible diagnosis of $\mathrm{Hb} \mathrm{J}$ Meerut was made and parental, as well as molecular studies were advised. Her mother also was detected as having $\mathrm{Hb} \mathrm{J}$ Meerut. Hemoglobin electrophoresis at alkaline $\mathrm{pH}$ showed a fast moving band ahead of $\mathrm{Hb} \mathrm{A}$. This variant is very uncommon with only few cases reported worldwide. ${ }^{[14-16]}$ A community based study in 3 districts of West Bengal namely Burdwan, 24 Parganas (North) and Midnapore (undivided) the prevalence rate of carrier state among antenatal mothers was found to be $5.95 \%$. ${ }^{[7]}$ The present study lacked the provision to rule out nutritional anemia in all cases by assay of serum iron, vitamin B12 and folate levels. DNA studies required particularly for those having borderline $\mathrm{Hb} \mathrm{A} 2$ levels in HPLC or the rare hemoglobin variants like $\mathrm{Hb} \mathrm{J}$ Meerut, was not done due to resource limitations. Illiteracy, ignorance, false fixed cultural beliefs existing in the community regarding screening tests during pregnancy attributed tonon-responders in study. Attrition, all spouses and parents not reporting in required cases also added to lacunae. Notwithstanding the limitations, the study gave an idea about prevalence of various hemoglobinopathies in this community and generated awareness in the local population. It also displayed significant association between $\mathrm{Hb} \mathrm{E}$ hemoglobinopathies and Rajbanshis. Individuals having $\mathrm{HbE}$ are usually asymptomatic even in homozygous states except some rare cases of $\mathrm{Hb} \mathrm{E}$ thalassemia which may manifest as thalassemia major. Therefore, to prevent the fatal and dreaded disease in next progeny (by combination between $\mathrm{Hb}$ Ehemoglobinopathies and beta thalassemia trait) the dire need for premarital, prenatal screening is emphasized. However, most cases of $\mathrm{Hb} \mathrm{E}$ being clinically asymptomatic, convincing the need for screening tests in individuals and recommending abortion (in required cases) appeared to be a tough call in the rural community. Fortunately, none of our HbE-hemoglobinopathy cases manifested as thalassemia major or intermedia. Addressing these social issues by mass media approach, policy reforms and by bringing head of the families and local people of eminence into confidence is urgently required. Explaining benefits of routine thalassemia screening, building up credibility of health-workers, having proper parental and spousal tests done as and when required and taking appropriate measures accordingly remain the mainstay. Prevention being the only cure for this incurable disease, intense awareness generation and conducting screening tests for carrier detection are mandatory. However a wider community based initiative addressing this grave issue is recommended.

\section{REFERENCES}

1. Choudhury VP, Kotwal J, Saxena R. Thalassemia screening and control programme. Paediatr Today 1998;1:283-9.

2. Verma IC, Saxena R, Thomas E, Jain PK. Regional distribution of $\beta$-thalassemia mutations in India. Hum Genet 1997;100:109-13.

3. Angastiniotis M. Epidemiology. In: GalanelloR, Eleftheriou A, Trager-Synodinos J, Old J, Petrou M, Angastiniotis M, editors. Prevention of thalassaemias and other haemoglobin Disorders, Vol. 1., Nicosia: Thalassaemia International Federation Publication; 2003. p. 10-2. 
4. Gajra B, Chakraborti S, Sengupta B. Prenatal diagnosis of thalassaemias. Int J Hum Genet 2002;2:173-8.

5. Desai M, Desai P. Do mothers with hemoglobinopathies and anemia require ironsupplementation in pregnancy? J Obstet Gynaecol India 1994;44:177-80.

6. Sinha M, Panigrahi I, Shukla J. Spectrum of anemia in pregnant Indian women and importanceof antenatal screening. Indian J Pathol Microbiol 2006;49:373-5.

7. Sur D, Mukhopadhyay SP. Prevalence of thalassemia trait in the state of West Bengal. J Indian Med Assoc 2006;104:11-5.

8. Piplani S. Hemoglobin E disorders in North East India. J Assoc Physicians India 2000;48:1082-4.

9. Colah RB, Gorakshakar AC, Nadkarni AH. Invasive and non-invasive approaches for prenatal diagnosis of haemoglobinopathies: Experiences from India. Indian J Med Res 2011;134:552-60.

10. Weatherall DJ. Hematologic methods. In: Weatherall DJ, editor. Methods in Hematology: Thalassemias.Vol. 6. Edinburg: Churchill Livingstone; 1983. p. 27-53

11. Dash AJ. Bengal District Gazeteers. Darjeeling. Alipore, Bengal: Bengal Govt. Press; 1947.

12. De M, Halder A, Podder S, Sen R, Chakrabarty S, Sengupta B, et al. Anemia and hemoglobinopathies in tribal population of Eastern and
North-eastern India. Hematology 2006;11:371-3.

13. Balgir RS. Scenario of hemoglobin variants in Central-East coast of India. Curr Sci 2006;90:1651-7.

14. Sachdev $\mathrm{R}$, Dam AR, Tyagi $\mathrm{G}$. Detection of $\mathrm{Hb}$ variants and hemoglobinopathies in Indian population using HPLC: Report of 2600 cases. Indian J Pathol Microbiol 2010;53:57-62.

15. Dinçol G, Güvenç S, Elam D, Kutlar A, Kutlar F. Hb J- Meerut $[\alpha 120(\mathrm{H} 3)$ Ala ->Glu ( $\alpha 1)$ ] in a Turkish Male. Int J Med Sci 2006;3:26-7.

16. Srinivas U, Mahapatra M, PatiHP. Hb J Meerut, a fast-moving hemoglobin A study of seven cases from India and a review of literature. Am J Hemato 2007;82:666-7.

How to cite this article: Ghosh N, Chakrabarti I, Chakraborty M, Goswami BK. A community based pilot study on prevalence of hemoglobinopathies among the antenatal women in a rural area of Darjeeling district, West Bengal. Int J Med Public Health 2013;3:107-10.

Source of Support: Nil, Conflict of Interest: None declared. 